\title{
Extraction of Dyes from Plant Sources and their application on Cotton and Wool using Mordants
}

\author{
*Varsha Kaur', Selvam Arjunan'2, and Indira Nanaiah' \\ 1. Department of Life Sciences, Center for Research and PG studies, Kristu Jayanti College (Autonomous), K \\ Narayanapura, Kothanur P.O, Bangalore - 560077, India. \\ 2. Department of Biotechnology, Faculty of Life \& Allied Health Sciences, Ramaiah University of Applied Sciences, \\ Bangalore - 560 054, India. \\ *Corresponding author: biosel2007@gmail.com
}

\begin{abstract}
Dyeing is an ancient art, which was practiced during the Bronze Age in Europe. Primitive dyeing techniques included sticking plants to fabric or rubbing crushed pigments into cloth. The methods became more sophisticated over time and techniques were developed using natural dyes from crushed fruits, berries and other plants, which were boiled into the fabric and gave light and water fastness [resistance].The widely and commercially used synthetic dyes impart strong colors but causes carcinogenicity and inhibition of benthic photosynthesis. Hence, use of natural dyes have become an importance in today's world. In this study, Natural dyes have been extracted from different plant sources namely, Beeta Vulgaris (Beetroot), Spinacia oleracea (Spinach), Ixora coccinea (Jungle Geranium), Brassica oleracea var. capitata f. rubra (Purple Cabbage), and Tagetes erecta (African Marigold) using mordants like $\mathrm{FeSO}_{4}$ and $\mathrm{CuSO}_{4}$ On Cotton and Wool. It was seen that Wool takes up the dye better than cotton because vegetable fibers like cotton take up less dye than animal fibers like wool and $\mathrm{CuSO}_{4}$ is a better mordant than $\mathrm{FeSO} 4$.
\end{abstract}

KeyWords Beeta Vulgaris, Spinacia oleracea, Ixora coccinea, Brassica oleracea var. capitata f. rubra, Tagetes erecta, Cotton and Wool

\section{Introduction:}

Dyeing is an ancient art, which predates written records. It was practiced during the Bronze Age in Europe. Primitive dyeing techniques included sticking plants to fabric or rubbing crushed pigments into cloth. The methods became more sophisticated over time and techniques were developed using natural dyes from crushed fruits, berries and other plants, which were boiled into the fabric and gave light and water fastness [resistance]. Presently there is an excessive use of synthetic dyes, estimated at around 10,000,000 tons per annum (Ghorpade.B., Darvekar.M. and Vankar, P.S.,2000). The production and application of which release vast amounts of waste and unfixed colorants, causing serious health hazards and disturbing the eco-balance of nature. The widely and commercially used synthetic dyes impart strong colors but causes carcinogenicity and inhibition of benthic photosynthesis (Adeel et al., 2009)Germany was the first to take initiative to put ban on numerous specific azo dyes for their manufacturing and applications. Nether lands, India and some other countries also followed the ban (Patel, 2011). Currently, ecological considerations are becoming important factors in the selection of consumer goods all over the world. Metal ions of mordants act as electron acceptors for electron donors to form co-ordination bonds with the dye molecule, making them insoluble in water. Alum, chrome, stannous chloride, copper sulphate, ferrous sulphate, etc., are the commonly used mordants. Cotton textile dyeing has been done since the medieval period using cheap natural dyes. Nature has gifted us more than 500 dye yielding plant species are coloring agents of these plants are derived from roots, leaves, barks, trunks or fruits. All colors of rainbow are obtained from plants. Natural dyes have better biodegradability and generally have higher compatibility with the environment. They are nontoxic, non-allergic to skin, non-carcinogenic, easily available and renewable. (Adeel et al., 2009; Pruthi et al., 2007; Saha and Dutta; Siva, 2007; Onal, 1996). Color fastness is the resistance of a material to change any of its color characteristics or extent of transfer of its colorants to adjacent white materials in touch. Generally light fastness, wash fastness and rub fastness are considered for textile fabrics. (Samanta and Agarwal, 2009)

Plants were the primary source of dye until the mid- $19^{\text {th }}$ century. That was when people discovered that dye pigments could be chemically produced. And so the process of natural dyeing became pretty much obsolete. Sources of natural dyes are everywhere. Dyes can be extracted from roots, foliage, nuts, berries and flowers. Until the mid-19th century plants were the primary source of dye. The process of natural dyeing became obsolete with the discovery that dye pigments could be produced through modern chemistry. Dyes produced by chemical means are more easily transferred to fibers, do not require as much time in preparation, and stand up better to repeated washing and exposure to sunlight. Today natural sources of dyes are used by artisans and crafters. Natural dyes are desirable mainly because of the quality of color that can be created with them. Dyes extracted from plants contain many different pigments, and thus are not the "pure" forms of pigment used in today's chemical dyes. These impurities create rich and sometimes unexpected color that can never be duplicated. For many the process of extracting the dyes from their natural sources connects them to their work, and gives them control over each step of creation. 
(Buchanan, Rita., 1999).

\section{Chemistry of Dyes:}

Dyes derived from natural materials such as plant leaves, roots, bark, insect secretions, and minerals were the only dyes available to mankind for the coloring of textiles until the discovery of the first synthetic dye in 1856. Rapid research strides in synthetic chemistry supported by the industrialization of textile production not only led to the development of synthetic alternatives to popular natural dyes but also to a number of synthetic dyes in various hues and colors that gradually pushed the natural dyes into oblivion. (Sujata Saxena and A. S. M. Raja, roadmap and sustainable textiles and clothing, 2014) natural dyes work best with natural fibers such as cotton, linen, wool, silk, jute, ramie and sisal. Among these, wool takes up dyes most easily followed by cotton, linen, silk and then the coarse fibers such as sisal and jute.

\section{Pigment description in the plant sources used:}

Beetroot: Betanin is the main coloring compound present in red beetroot juice color. Historically, it has imparted additional color to wines. The colorings responsible for the red hue of the juice are a group of molecules called betalains. Red Cabbage: The purple color in red cabbage comes from a class of pigment molecules called anthocyanins. Anthocyanins are found in flower petals, leaves and stems. Anthocyanins are plant pigments also known as flavonoids and produce red, pink, violet and magenta colors in the various plant parts. The anthocyanidin group controls the color of the pigment. Spinach: Spinach leaves, contain chlorophyll $a$, chlorophyll $b$ and $b$-carotene as major pigments as well as smaller amounts of other pigments such as xanthophylls. Marigold flowers: Marigold flowers [Tagetes], which are yellow to orange red in colour, are a rich source of lutein, a carotenoid pigment. This pigment has acquired greater significance because of its excellent colour value. Ixora flowers: Anthocyanin pigments of Ixora flowers are used for dyeing purpose. (Rupali Deshpande, 2011) Ixora contains, leucocyanidin, anthocyanins, proanthocyanins, which impart the color to the flowers. The anthocyanidin group controls the color of the pigment.

\section{METHODOLOGY:}

\section{WASHING:}

Cotton cloth and Wool ball is brought and were washed and soaked in distilled water overnight. And then cotton was cut into square pieces and wool was cut into strands. This is done to get rid of the starch and stiffness of the cloth.

\section{SCOURING OF THE CLOTH:}

Scouring of cotton and wool was done, where the cloth was put into $\mathrm{Na} 2 \mathrm{CO} 3$ with distilled water and boiled for two hours at 80 degree and then air dried for a night. This is done to remove the impurities and also the hydrophobic character which is present in the fiber.
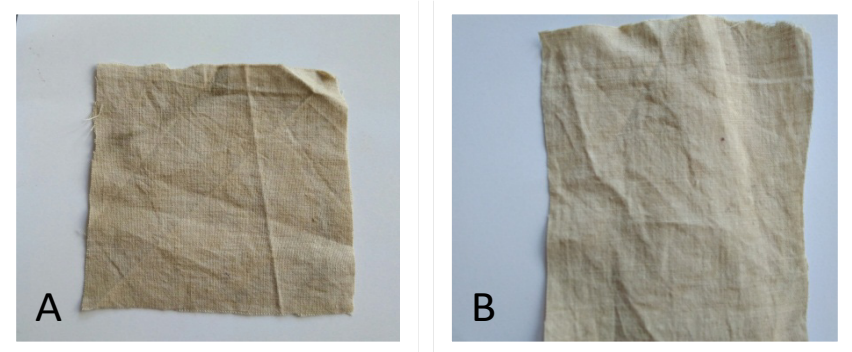

Figure 1: Beeta Vulgaris (Beetroot) Color taken by the cotton -A: stained with $\mathrm{FeSO} 4$ mordant; B: With CuSO4 mordant
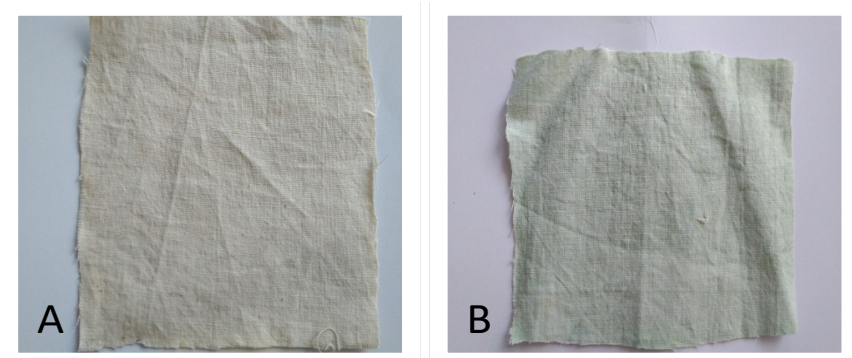

Figure 2: Spinacia oleracea (Spinach) Color taken by the cotton -A: stained with $\mathrm{FeSO} 4$ mordant; B: With CuSO4 mordant
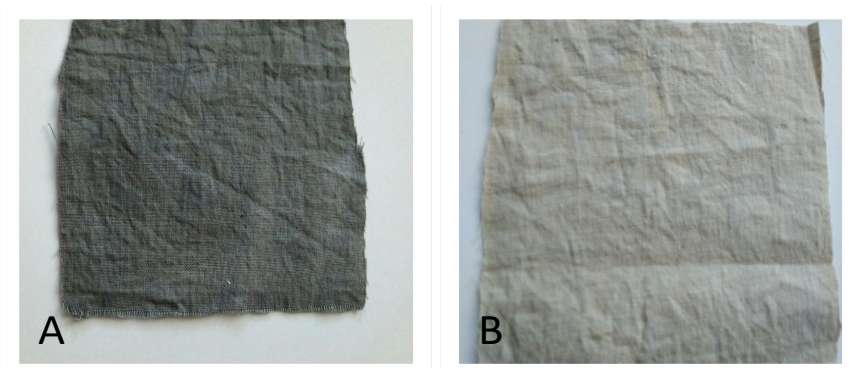

Figure: 3 Ixora coccinea (Jungle Geranium) Color taken by the cotton -A: stained with FeSO4 mordant; B: With CuSO4 mordant

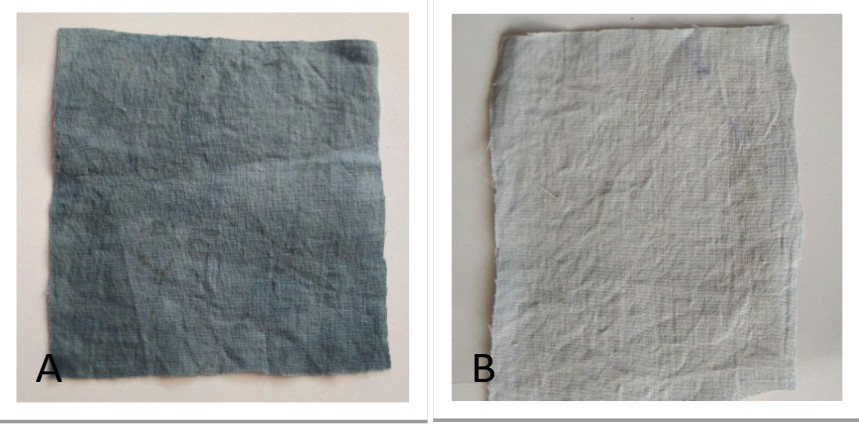

Figure 4: Brassica oleracea var. capitata f. rubra (Red Cabbage) Color taken by the cotton -A: stained with FeSO4 mordant; B: With CuSO4 mordant

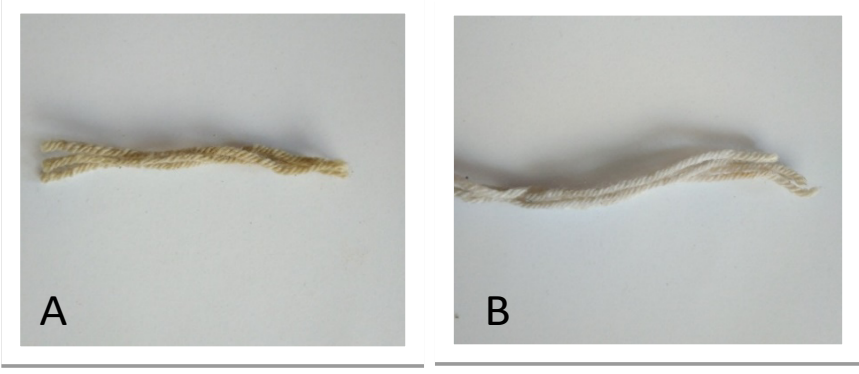

Figure 5: Tagetes erecta (African Marigold) Color taken by the cotton -A: stained with $\mathrm{FeSO} 4$ mordant; B: With CuSO4 mordant 

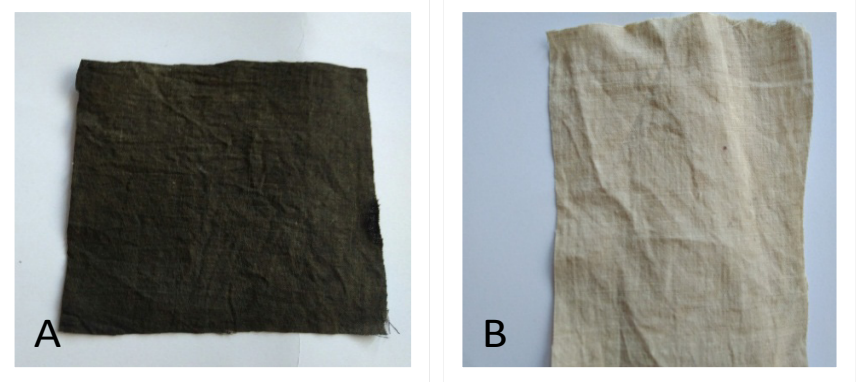

Figure 6: Beeta Vulgaris (Beetroot) Color taken by the cotton -A: stained with FeSO4 mordant; B: With CuSO4 mordant
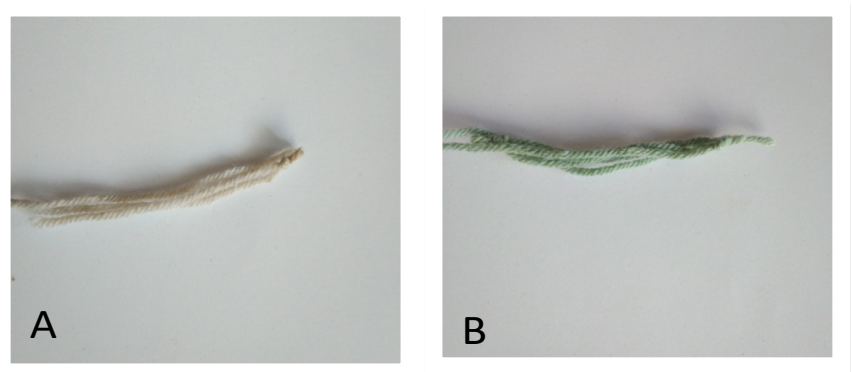

Figure 7: Spinacia oleracea (Spinach) Color taken by the cotton -A: stained with FeSO4 mordant; B: With CuSO4 mordant

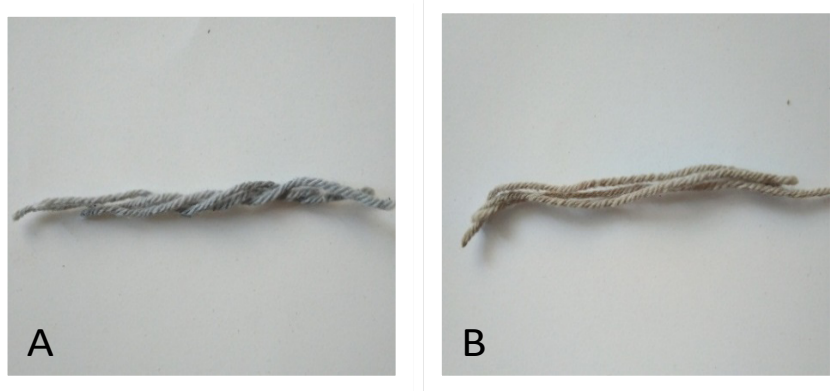

Figure 8: Ixora coccinea (Jungle Geranium) Color taken by the cotton -A: stained with FeSO4 mordant; B: With CuSO4 mordant

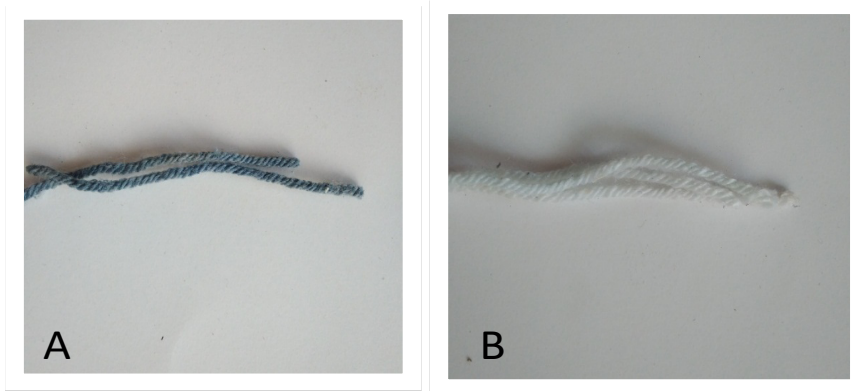

Figure 9: Brassica oleracea var. capitata f. rubra (Red Cabbage) Color taken by the cotton -A: stained with FeSO4 mordant; B: With CuSO4 mordant

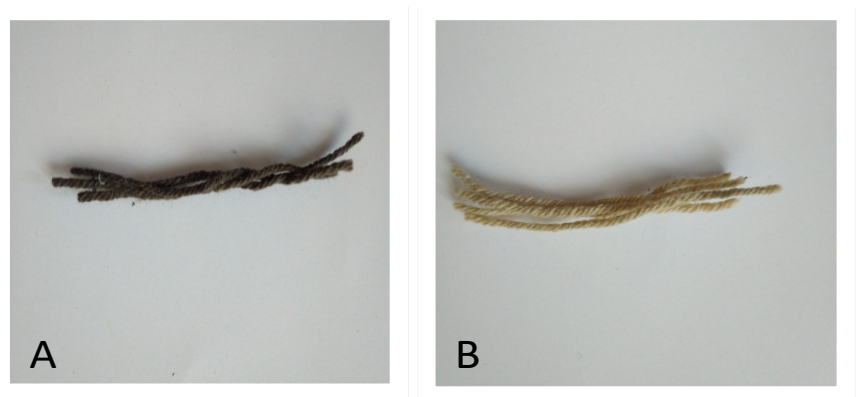

Figure 10: Tagetes erecta (African Marigold) Color taken by the cotton -A: stained with FeSO4 mordant; B: With CuSO4 mordant

\section{MORDANTING AND DYE EXTRACTION:}

The material then was mordanted with $\mathrm{FeSO}_{4}$ in distilled water for one hour in water bath and then air dried. Also, dye extract was being prepared on the same day, the plant material was taken and grinded well and then the juice of it was taken, and then filtered.

\section{THE DYEING:}

The cloth pieces were then soaked in the dye and boiled for an hour in the water bath and then left for overnight. The cloth pieces were taken out of the dye and air dried. They were then washed and dried. Similar method was carried out with CuSO4 mordant for all the plant materials.

\section{RESULTS:}

According to the observation of figure 1-15 Wool absorbs the dye better and $\mathrm{CuSO}_{4}$ is a better mordant. Wool takes up dye better than cotton. Wool takes up the dye better than cotton because vegetable fibers like cotton take up less dye than animal fibers like wool. Wool is one of the best fabrics to dye as the color will penetrate the core of the fabric and permanently bond with the fibers. Wool is versatile and takes many different colors and dyes. They are more complex than cellulose, which is made out of repeating units of a sugar, glucose, and thus there are more ways in which different dye chemicals can attach to them than to cotton. CuSO 4 is a better mordant than FeSO4. This is because it retains the dye color to a greater extent.CuSO4 is a better mordant also because, protein fibers like wool are very sensitive to iron and too high concentrations or overexposure can damage the fiber and/or make. The results of the colors taken by the cotton and wool fibers are depicted in the figure below.

\section{DISCUSSION:}

India has a rich plant biodiversity which is ranked 11th as biggest biodiversity in the world. It has approximately 490,000 plant species and there is no doubt that the plant kingdom is a treasure-house of diverse natural products (Neha Grover et al., (2011). One such product from nature is the dye. Pigment from leaves, fruits, seed, wood and roots were used as dye stuff for textiles and as paint in art and craft. Natural dyes are environmental friendly, hygienic, user friendly and permanent than another colorant. The replacement of natural dyes could happen until the introduction of synthetic dyes due to feasible coloring property of natural dyes (Kumaresan et al., (2011)). Certain problems with the use of natural dyes in textile dyeing are color yield, complexity of dyeing process, reproducibility results, limited shades, blending problems and inadequate fastness properties (Sachan and Kapoor (2007); Siva (2007). But these problems can be overcome by using chemicals called as mordants. Mordants are metal salts which produce an affinity between the fabric and the dye 
(Vankar et al., (2009); Samantha and Agarwal,(2009). Oneofthe pleasures of using natural dye is that no two baths will ever give exactly the same result, there will be an element of surprise with variation accordingly to the season, the weather, the maturity of the plant, its position in the sun or shade and the quality of the water used for dyeing will determine the dyeing quality. Recently, interest in the use of natural dyes has been growing rapidly due to the result of stringent environmental standards imposed by environmental board and pollution control board of many countries in response to toxic and allergic reactions associated with synthetic dyes (Kamel et al., (2005). Research has shown that synthetic dyes are suspected to release harmful chemicals that are considered to be high pollutant in both water and land which would be allergic, carcinogenic and detrimental to human health. Natural dyes from

petrochemical based dyes and if harvesting is carefully managed without affecting environmental and social benefits. Natural dyes not only release medicinal properties but also improve the aesthetic value of the product and they are unique and ecofriendly (Neha Grover et al., (2011).

\section{ACKNOWLEDGEMENT:}

We would like to acknowledge, Dr. Indira Nanaiah, Department of Life Sciences, Center for Research and PG studies, Kristu Jayanti College (Autonomous), K Narayanapura, Kothanur P.O, Bangalore - 560077, India.

Financial support and sponsorship: Nil

Conflicts of interest: There are no conflicts of interest.

\section{References:}

1. Adeel M, ljaz A, Aleem M, theriogenology,71(8),1220-1225,2009.

2. Ejoba Raphael., Phytochemical constituents of some leaves extract of Aloe vera and Azadirachta indica plant species, Global Advanced Research, Journal of Environmental Science and Toxicology Vol. 1(2) pp. 014-017.2012.

3. Harborne, J.B. Phytochemcial methods London, Chapman and Hall, Ltd., pp 49-188.3,Jigna Parekh, Sumitra V. Chanda (2007). In vitro Antimicrobial Activity and Phytochemical Analysis of Somelndian Medicinal Plants, Turk J Biol 31. 53-58.4. 1973.

4. Hofenk de Graaf, Judith The Colourful Past: Origins, Chemistry and Identification of Natural Dyestuffs. Abegg-Stiftung and Archetype Publications. 2004

5. Jayamala M, Vijila Christy and Ranjith Singh, 23275146 GMO, volume 3,2015.

6. Jenkins, David, ed. The Cambridge History of Western Textiles (2 vols.). Cambridge University Press. 2003.
7. Kerridge, Eric, Textile Manufactures in Early Modern England Manchester University Press. 1988.

8. Kulkarni S S, Gokhale A V, Bodake U M, Pathade G R, ISSN: 2249-0256, 21st August, 2011.

9. M. Jahangir, H. K. Kim, Y. H. Choi, and R. Verpoorte, "Health-affecting compounds in Brassicaceae," Comprehensive Reviews in Food Science and Food Safety, vol. 8, no. 2, pp. 31-43, 2009.)

10. M. Jahangir, H. K. Kim, Y. H. Choi, and R. Verpoorte, "Health-affecting compounds in Brassicaceae," Comprehensive Reviews in Food Science and Food Safety, vol. 8, no. 2, pp. 31-43, 2009.

11. Netherton, Robin, \& Owen-Crocker, Gale R., eds. Medieval Clothing and Textiles. 3. Boydell Press. 2007.

12. Nital patel,,Ajit Datar, Extraction, stability and separation of anthocyanins of Ixora coccinea, International journal of Pharmacy and Pharmaceutical sciences, vol7, issue 32014.

13. Parry, Linda ,William Morris Textiles. Viking Press. 1983.

14. Saxena, S. and Raja, A. Natural Dyes: Sources, Chemistry, Application and Sustainability Issues. In: Muthu, S., Eds., Roadmap to Sustainable Textiles and Clothing. Textile Science and Clothing Technology, 2014.

15. Schoeser, Mary. Silk. Yale University Press. 2007

16. Shyam Barhanpurkar, Alok Kumar, Roli Purwar International Journal of Polymer and Textile Engineering, ISSN: 2394-2592, Volume 2,2015.

17. Thilagavathi, G., \&KrishnaBalaS. Microencapsulation of herbal extracts for microbial resistance inhealth care textiles. Indian Journal of Fibre \& Textile Research, 32. pp: 351-354.15. 2007.

18. Thompson, Frances; Thompson, Tony (1987). Synthetic Dyeing: for Spinners, Weavers, Knitters and Embroiderers. David \& Charles. 1987.

19. Tozer, Jane; Levitt, Sarah, Fabric of Society: a Century of People and their Clothes 1770-1870. Laura Ashley Press. 1983.

20. Vankar, P. S., Shankar, R. and Wijayapala, S. Dyeing Cotton, Silk and Wool Yarn with Extract of Garnicia mangostana Pericarp. JTATM, 6(1), 2009 